\title{
Evaluation of soil characteristics of sunflower growing shrink-swell soils of Eastern Vidarbha
}

\author{
N.S. WAGH, D.K. MANDAL, A.S. GAJARE AND N.S. SADANSHIV
}

Received : 07.07.2014; Revised : 25.09.2014; Accepted : 13.10.2014

MEMBERS OF RESEARCH FORUM:
Corresponding author :
N.S. WAGH, Department of Soil
Science and Agricultural Chemistry,
Dr. Panjabrao Deshmukh Krishi
Vidyapeeth, AKOLA(M.S.) INDIA
Email: nwagh98@ gmail.com

Co-authors :

D.K. MANDAL, National Bureau of Soil Survey and Land Use Planning (NBSS \& LUP), NAGPUR (M.S.) INDIA Email: dkmandal@nbsslup.ernet.in

A.S. GAJARE AND N.S. SADANSHIV, Department of Soil Science and Agricultural Chemistry, Dr. Panjabrao Deshmukh Krishi Vidyapeeth, AKOLA (M.S.) INDIA

Email: yawalkar333@gmail.com, nil.sadanshiv@gmail.com

\section{Summary}

The sunflower growing soils of eastern Vidarbha region have been investigated for assessing the agro environmental suitability. Six pedons from high intensity area of Bhiwapur and Umred of Nagpur district were selected for study. Crop yield data were collected during field survey and other physical and chemical properties were studied in the laboratory and yields were correlated with soil properties. The investigation revealed that high intensity sunflower growing soils belonged to Typic Haplusterts, alkaline in reaction ( $\mathrm{pH} 8.2$ to 8.7) and low to medium in organic carbon content $(0.24$ to $0.79 \%)$ and high cation exchange capacity (47.91 to 58.71 $\%$ ), calcium carbonate were $<5$ per cent, $\mathrm{Ca}: \mathrm{Mg}$ ratio varied from 1.8 to 2.6 indicating moderate drainability and base saturation ( 85 to $89 \%$ ). Among the DTPA- extractable micronutrients, zinc was low while the soils were medium to high in manganese and iron and low to high in copper content. The sunflower yield when correlated with agro edaphic parameters it was found that rainfall and major soil physical and chemical characteristics influenced the crop yield. The stepwise regression analysis of sunflower yield with agroenvironment properties reveal that Typic Haplusterts distributed over four villages of Bhiwapur and Umred tahsils of Nagpur district that $\mathrm{pH}, \mathrm{Ca}, \mathrm{Na}$, sum of cations, CEC, ESP, Mn, sand, clay and water retention at $1500 \mathrm{kPa}$ had positive correlation. The high correlation co-efficient obtained with water retention at $33 \mathrm{kPa}$ (0.91), post Kharif rainfall (0.90), clay (0.87) and water retention at $1500 \mathrm{kPa}(0.72)$ indicating yield influencing factors.

Key words : Shrink-swell soils, Oilseed, Vidarbha

How to cite this article : Wagh, N.S., Mandal, D.K., Gajare, A.S. and Sadanshiv, N.S. (2014). Evaluation of soil characteristics of sunflower growing shrink-swell soils of Eastern Vidarbha. Asian J. Soil Sci., 9(2): 187-191. 